\title{
A SHORT OVERVIEW OF TRANSPORT IN 2014
}

\author{
Raimundas Junevičius ${ }^{1}$, Olegas Prentkovskis ${ }^{2}$ \\ ${ }^{1}$ Managing (Associate) Editor, E-mail: raimundas.junevicius@vgtu.lt \\ ${ }^{2}$ Editor-in-Chief, E-mail: olegas.prentkovskis@vgtu.lt
}

The research journal TRANSPORT is published by Vilnius Gediminas Technical University in partnership with the Lithuanian Academy of Science and Taylor \& Francis

\section{November 2014}

It is widely known that the concept of transport (or transportation) covers a wide range of applications for the movement of people and goods. A variety of transport modes ensures connection by air, rail, road, water, cables, pipelines and space. Accordingly, infrastructure, vehicles and operations are the most important components of the field, which enables trade relations - the prerequisite for the development of civilizations.

The Editorial Board of the research journal TRANSPORT presents a short summary of topics, which were published in Volume 29, Issues 1-4 of 2014.

In 2014, authors submitted scientific publications on a wide variety of topics of interest. Scientific articles can be divided into two basic sections:

- The first section is dedicated to solutions of technical problems pertaining to transport and related fields. Such scientific problems encompass traffic safety and the optimisation of cargo flow movements as well as the control of: road transport movement, trains and cargos transported by trains, ship movement and container flows in terminals.

- The second section focuses on the scientific solution to problems that occur in management of transportation processes, namely, the control algorithms searching for the optimal movement of cargos, passengers or means of transport, route planning, and the optimal management of a terminal.

This year, the Special Issue on Travel Demand Management of the research journal TRANSPORT was published for the first time. It was published as the third Issue of 2014 - TRANSPORT 29(3) 2014, http://www.tandfonline.com/ toc/tran/29/3.

The Invited Editors were:

- Prof. Ying-En Ge (Shanghai Maritime University, China);

- Prof. Wafaa Saleh (Edinburgh Napier University, United Kingdom);

- Prof. Michael G. H. Bell (University of Sydney Business School, Australia).

Publications of the research journal TRANSPORT published in 2014:

\begin{tabular}{|c|c|c|c|c|}
\hline Type Issue & TRANSPORT 29(1) & TRANSPORT 29(2) & TRANSPORT 29(3) & TRANSPORT 29(4) \\
\hline Original articles & 14 & 13 & 11 & 12 \\
\hline Book reviews & - & 1 & 1 & - \\
\hline Editorials & - & - & 1 & 1 \\
\hline Reports & - & - & - & 1 \\
\hline
\end{tabular}

The research journal TRANSPORT has a wide range of readers. This result would have been impossible without the authors who decided to publish results of their scientific researches in the research journal TRANSPORT and reviewers who helped us to ensure the selection of high-quality scientific publications. As we aim to make the research journal TRANSPORT even more appealing, authors are invited to submit various publications, ranging from topics regarded more or less usual for the research journal TRANSPORT as well as those offering an unconventional point of view or alternative solutions to problems of transport or related fields.

The report 'The research journal TRANSPORT: peer-reviewing process in 2014' is available on the last pages of the Current Issue: http://dx.doi.org/10.3846/16484142.2014.992150 